\title{
TRIBUTOS FEDERAIS PIS/PASEP E COFINS: O APROVEITAMENTO DOS CRÉDITOS NO RAMO AUTOMOBILÍSTICO
}

\author{
Lucas Almeida dos Santos \\ Universidade Federal de Santa Maria \\ Centro universitário Franciscano \\ Brasil \\ Priscila da Silva Vilagrand \\ João Friedrich
}

Data de submissão: 15/07/2017

Data de aceite: 05/02/2018

\begin{abstract}
RESUMO
O presente artigo que tem como objetivo analisar a apuração dos créditos do PIS e da Cofins e seu aproveitamento para apuração de impostos em uma concessionária de automóveis de atuação no mercado nacional, no sistema não cumulativo, apresenta-se como um de estudo de caso de natureza qualitativa, que de acordo com os objetivos propostos possui caráter descritivo e exploratório. Ademais, utilizou-se também das técnicas de coleta de dados bibliográfica e documental como forma de complementar o estudo. Dentre os principais resultados encontraram-se créditos que ainda não eram utilizados pela empresa, representando estes, entre os meses de Janeiro à Junho um total de R \$ 125.345,99 referente aos créditos do PIS e da Cofins não aproveitados. Ainda, percebeu-se que se a empresa tivesse um planejamento tributário, poderia reduzir seus gastos com tributos, passando a investir em outros setores para melhorar seu desempenho organizacional.
\end{abstract}

Palavras-chave: Créditos; PIS; Cofins; não cumulatividade;

\section{ABSTRACT}


The purpose of this article is to analyze the calculation of PIS and Cofins credits and their use for tax calculation in a car dealership operating in the national market, in the non-cumulative system, is presented as a case study of qualitative nature, which according to the proposed objectives has a descriptive and exploratory character. In addition, the techniques of collecting bibliographical and documentary data were used as a way to complement the study. Among the main results were found credits that were not yet used by the company, representing between January and June a total of $\mathrm{R} \$$ 125,345.99 referring to unused PIS and Cofins credits. Also, it was realized that if the company had a tax planning, it could reduce its expenses with taxes, starting to invest in other sectors to improve its organizational performance.

Keywords: Credits; PIS; Cofins; Cumulative not;

\section{INTRODUÇÃO}

Atualmente as Ciências Contábeis correspondem, também, há um conjunto de registros, que permitem apurar as informações patrimoniais e os eventos ocorridos dentro das entidades. Neste sentido a contabilidade propicia aos gestores uma maior assertividade no processo decisório, pois a mesma é responsável por gerar informações em tempo real.

A contabilidade, dentre outras funções, se responsabiliza pela constituição societária da empresa, sua situação legal perante aos órgãos cadastrais e tributários, o acompanhamento dos seus resultados econômico-financeiros, além de fazer uso de sistemas eficazes de controle interno contábil-administrativo e das suas demais áreas.

A partir da década de 1980, uma nova ordem mundial emergiu alterando as estruturas dos mercados financeiros e promovendo o aparecimento de grandes corporações transnacionais. Com a globalização, vários países desenvolvidos e aqueles em desenvolvimento, entre os quais está o Brasil, bem como suas respectivas culturas, foram atingidos, gerando crises financeiras e políticas com a reorganização de seus mercados internos.

Como uma ciência, a contabilidade surge com intuito de planejar a vida das empresas e cuidar de seus interesses frente a uma sociedade competitiva e cada vez mais exigente. Conceitualmente, Ribeiro (1999, p. 33), elucida que a "contabilidade é a ciência que estuda e pratica as funções de orientação, de controle e de registro relativas à administração econômica”. Esse conceito demonstra a preocupação remanescente da contabilidade com o estudo e prática das suas funções. 
Contudo, há outro fator ainda mais relevante que, faz do Brasil um dos países com a maior mortalidade empresarial do planeta: a carga tributária. Portanto, os tributos têm sua origem na Antiguidade e servem para regular e possibilitar a vida em sociedade, mediante a contribuição individual de cada pessoa em favor da comunidade. No Brasil, além de comporem uma malha intricada e superposta de obrigações, os tributos constituem uma tarefa complexa e onerosa, e apresenta um perfil de carga pesadíssima sobre as atividades produtivas das empresas com que crescem a cada ano (ANDRADE, LINS, BORGES; 2015).

Outrora, em 1970 foi criado o Programa de Integração Social (PIS) pela Lei Complementar $n^{\circ} 7$, esta contribuição sofreu diversas alterações ao longo do tempo, estando atualmente embasada na Lei $\mathrm{n}^{\circ} 9.715$ (resultante da conversão da MP $\mathrm{n}^{\circ}$ 1.212/95), publicada no Diário Oficial da União em 26-11-96. O Ato Declaratório no 39, DOU de 29-11-1995, trouxe o detalhamento do tratamento a ser dado a esta contribuição a partir de outubro 1995. Esta legislação sofreu importantes alterações, a partir da competência fevereiro de 1999, por meio da MP nº 1807/99, cujo número atual é 2.158-35/2001. Contudo, inúmeras alterações foram procedidas por meio das Leis nos 10.637/02, 10.833/03, 10.865/04 e 10.925/04. Devemos considerar, ainda, que, especificas como é o caso, por exemplo, da Lei $n^{\circ} 10.485 / 02$ para o setor automotivo.

Outro tributo, objeto de análise no presente estudo, é a Contribuição para Financiamentos da Seguridade Social (Cofins), que foi criada pela Lei Complementar $n^{\circ}$ 70/91, esta contribuição sofreu importantes alterações a partir da competência fevereiro de 1999, com base na Lei n 9.718, publicada no Diário Oficial da União em 28-11-98. Por sua vez, a Lei $\mathrm{n}^{\circ} 9.718$ sofreu alterações por meio da MP $\mathrm{n}^{\circ} 1807$, cujo número atual é 2.158-35/2001.

Levando-se em consideração a legislação supracitada do PIS e da Cofins sob as regras deste regime, as pessoas jurídicas de direito privado e as que lhe são equiparadas pela legislação do imposto de renda, desde que apurem o IRPJ com base no Lucro Real. Com isso, tanto o PIS quanto a Cofins passaram a vigorar e a conviver em dois sistemas: o não cumulativo e o cumulativo, fato que torna a legislação cada vez mais complexa.

A Constituição Federal de 1988 adotou o princípio da não-cumulatividade no âmbito do direito tributário brasileiro, inicialmente com relação ao Imposto sobre 
Produtos Industrializados (IPI) e ao Imposto sobre Circulação de Mercadorias e Serviços, (ICMS) estendendo-o, posteriormente, às contribuições sociais PIS/Pasep e Cofins. Porém, apesar de serem duas contribuições federais, com destinações diferentes, criadas em épocas diversas da história política e econômica, as mesmas incidem sobre o faturamento. De acordo com Fabretti (2015), tanto o PIS quanto a Cofins tornaram-se tributos não cumulativos pelas Leis nos 10.637/02 (PIS) e 10.833/03 (Cofins). Neste sentido o regime de incidência não cumulativa foi instituído para o PIS, em dezembro de 2002 através da Lei $n^{\circ} 10.637 / 2002$, enquanto a Cofins acompanhou esta metodologia a partir de 2004 com a Lei nº10.833/2003.

Ainda acerca do regime de incidência não cumulativo, este admite o direito a crédito relativo a entrada de mercadorias, bens e serviços no estabelecimento do contribuinte, além de permitir o desconto de créditos apurados com base em custos, despesas e encargos da pessoa jurídica, conforme dispositivos legais. Considerando-se que proposta do presente estudo é proporcionar um enlace entre a teoria e a prática, esta pesquisa tem como objetivo geral analisar a apuração dos créditos do PIS e da Cofins e seu aproveitamento para apuração de impostos em uma concessionária de automóveis com atuação no mercado nacional, no sistema não cumulativo.

\section{REFERENCIAL TEORICO}

Nesta seção será abordado a literatura vigente acerca da temática abordada, tendo como parâmetros para a construção do referencial a contabilidade tributária, o PIS e a Cofins.

\subsection{Contabilidade Tributária}

A Contabilidade Tributária pode ser entendida com um ramo da Contabilidade que trata especificamente do estudo, do gerenciamento e da contabilização de tributos. Os tributos poderão ser devidos aos governos federais, estaduais e municipais, conforme a natureza da operação que da origem ao respectivo tributo. Assim, os tributos mais importantes são aqueles incidentes sobre o faturamento, o lucro e a folha de pagamento. Contudo, há uma infinidade de tributos que as entidades recolhem aos cofres públicos, sejam da modalidade impostos, taxas, contribuições de melhoria, empréstimos 
compulsórios ou contribuições sociais, cujas obrigações surgem em consequência da ocorrência dos respectivos fatos geradores (PORTAL TRIBUTÁRIO, 2016).

Os fatos geradores de tributos estão por toda parte: nas compras, na produção e vendas de bens, na contratação e prestação de serviços; no pagamento de salários; nas importações e nas exportações; nos resultados derivados de transações financeiras; e no transporte de cargas ou de passageiros (PAULSEN; MELO, 2011).

\subsection{Programa de Integração Social (PIS)}

O PIS ou Programa de Integração Social, estabelecido por meio da Lei Complementar de $\mathrm{n}^{\circ}$ 07/1970, é utilizado para integrar o funcionário na história existencial, bem como no desenvolvimento da empresa. Desde 1988, com base na Constituição Federal, as arrecadações do PIS são repassadas para o programa de segurodesemprego, e abono salarial.

O PIS de acordo com a Lei Complementar de $n^{\circ}$ 07/1970, possui duas formas de pagamento e recolhimento: PIS cumulativo e PIS não cumulativo. A empresa que se enquadra no Simples Nacional, contribui o PIS, mas não se necessita efetuar o pagamento separadamente. Mensalmente, o PIS é incluído no pagamento integrado de impostos e contribuições. Já na modalidade não cumulativa, o PIS é uma maneira de contagem da contribuição, de modo que a empresa faz o desconto sobre o faturamento e pode se creditar sobre compras e determinadas despesas.

Dessa forma, o PIS não cumulativo é aplicável as empresas de direto privado, ou ainda aquelas que são salvaguardadas pela legislação do IR, tributadas pelo lucro real. A maior parte das pessoas jurídicas de serviços, contribui o PIS e Cofins com base no lucro presumido, pois esta é uma forma mais simplificada. O PIS no regime cumulativo possui alíquota de 0,65\% e o PIS não cumulativo possui alíquota de 1,65 (PORTAL TRIBUTÁRIO, 2016).

\subsection{Contribuição para Financiamento da Seguridade Social (Cofins)}

A Cofins é a Contribuição para Financiamento da Seguridade Social, esta foi constituída pela Lei Complementar de $n^{\circ}$ 70/1991. São contribuintes da Cofins as 
pessoas jurídicas de direito privado em geral, inclusive as pessoas a elas equiparadas pela legislação do Imposto de Renda, exceto as microempresas e as empresas de pequeno porte optantes pelo Simples Nacional (LC 123/2006).

Assim como o PIS, a Cofins também pode ser não cumulativa. Esta ocorre quando a obtenção total de receitas independe de sua designação ou mesmo classificação contábil, pois o que realmente importa é o pagamento mensal da pessoa jurídica. Em tal modalidade, não cumulativa, a apuração da contribuição é debitada pela empresa, sobre o faturamento da mesma. Dessa forma, a empresa se credita através das compras e despesas específicas (FABRETTI, 2015). Ainda, a tributação deve ocorrer para empresas tributadas por meio do valor real. Com a alíquota de 7,6\% da Cofins não cumulativa, as empresas devem fazer o cálculo aproveitando créditos relacionados com bens adquiridos para fins de revenda ou insumo na prestação de serviços e fabricação de produtos para venda.

\subsection{Diferenças entre a incidência cumulativa e incidência não cumulativa}

A partir da competência dezembro de 2002, para fins de cálculo do PIS/Pasep, de acordo com a Lei $n^{\circ} 10.637-2002$, é preciso que se faça uma separação entre o critério de incidência cumulativa e incidência não cumulativa. Esse mesmo tratamento passou a ser aplicado a Cofins a partir de 1 de fevereiro de 2004, de acordo com a Lei $n$ 10.833/03, conforme poderá ser visualizado no quadro 1 .

Quadro 1 - Comparativo das incidências cumulativas e não cumulativas

\begin{tabular}{|l|l|}
\hline Incidência Cumulativa & Incidência Não Cumulativa \\
\hline $\begin{array}{l}\text { Alíquota de 0,65\% para o PIS e 3\% ou 4\% } \\
\text { para a Cofins }\end{array}$ & $\begin{array}{l}\text { Alíquota de 1,65\% para o PIS e 7,6\% para a } \\
\text { Cofins }\end{array}$ \\
\hline Não se pode utilizar créditos. & Permitida a utilização de créditos. \\
\hline $\begin{array}{l}\text { Aplica-se a pessoas jurídicas tributadas pelo } \\
\text { lucro presumido ou arbitrado e não se aplica } \\
\text { a pessoas jurídicas tributadas pelo lucro real, } \\
\text { exceto nos casos específicos previstos em } \\
\text { Lei. }\end{array}$ & $\begin{array}{l}\text { Não pelo lucro presumido, arbitrado e optantes } \\
\text { pelo SIMPLES NACIONAL. }\end{array}$ \\
\hline
\end{tabular}

Fonte: Adaptado de PINTO (2012). 
Fazendo uma analogia do quadro acima se percebe que as alíquotas incidentes sobre a receita bruta no regime cumulativo (0,65\% PIS e 3\% Cofins) são bem menores do que as incidentes no regime não-cumulativo (1,65\% PIS e 7,6\% Cofins), porém neste último tem-se a possibilidade de aproveitar-se de créditos nas aquisições de insumos para deduzir da base de cálculo o que beneficia muito na apuração destas contribuições em uma indústria por exemplo, já não se pode falar o mesmo nas prestadoras de serviços.

O regime da não-cumulatividade, apesar de ter uma alíquota maior, de 9,25\%, para as duas contribuições, surgiu com o objetivo de reduzir a carga tributária das empresas que utilizam insumos e matéria-prima. Isto porque este permite que insumos e matérias-primas gerem créditos que são abatidos do valor final a ser recolhido de PIS e da Cofins. No entanto, para as empresas que utilizam poucos insumos ou nenhum, como é o caso das prestadoras de serviço, onde sua principal matéria-prima é a mão de obra e não gera direito a crédito dessas contribuições estarem na não- cumulatividade acarreta um considerável aumento na carga tributária (PINTO, 2012).

\subsection{Definição de insumo}

Apesar da relevância para as pessoas jurídicas, a não cumulatividade do PIS e da Cofins, o conceito de insumo para fins dessas contribuições não foi corretamente definido pela legislação tributária, tendo a Secretaria da Receita Federal do Brasil (SRF), por meio da Instrução Normativa (247/2002) conceituado como insumos apenas os bens e serviços efetivamente consumidos ou desgastados durante a fabricação de produtos ou prestação de serviços.

A Receita Federal do Brasil (RFB), que em suas soluções de consulta vem se manifestando nessa linha restritiva, apenas tomou por empréstimo a definição de insumos na fabricação de produtos já existente para o Imposto sobre Produtos Industrializados (IPI), segundo a qual somente os insumos efetivamente consumidos ou desgastados em razão do contato direto com o produto em fabricação conferem crédito do referido imposto (IR, 247/2002). 
Contudo, em relação ao IPI tal conceito está relacionado a própria materialidade desse tributo, cujo fato gerador corresponde a industrialização de produtos. Já em relação ao PIS e a Cofins, a materialidade dessas contribuições vai além da atividade meramente mercantil, fabril ou de serviços, alcançando todas as receitas auferidas pela pessoa jurídica, motivo pelo qual o conceito de insumos não pode simplesmente ser tomado por empréstimo da legislação do IPI (LUNARDELLI, 2003).

Ainda, conforme o autor supracitado, atualmente há uma corrente doutrinaria e jurisprudencial de que o conceito de insumo dever ser aquele de despesa necessária previsto na legislação do Imposto de Renda de Pessoa Jurídica (IRPJ), que define como dedutíveis para fins deste imposto os custos e despesas necessários a atividade da empresa. Ricardo Mariz de Oliveira é um dos maiores defensores dessa tese, de que são insumos todos os custos de produção e despesas que contribuam para a produção.

Também Bravo (2015) elucida que há o entendimento mais restritivo, manifestando em decisões recentemente publicadas de Tribunais Administrativos e Judiciais, de que não deve prevalecer o critério aplicado pela legislação do IRPJ, pois nem sempre as despesas necessárias são essenciais, ou seja, aquelas cuja ausência importa na impossibilidade da produção ou da prestação do serviço.

\subsection{Créditos do PIS e da Cofins admissíveis}

Tendo em vista o regime tributário instituído da não cumulatividade das contribuições ao PIS e a Cofins permitir a possibilidade do contribuinte se creditar das referidas contribuições e efetuar o recolhimento pelo que seria denominado valor agregado, a legislação então vigente dá margem a várias interpretações do que daria direito ao referido crédito, principalmente no que diz respeito ao conceito de insumo, que pode variar de contribuinte a contribuinte.

Segundo as Leis $\mathrm{n}^{\text {os }} 10.637 / 2002$ e $10.833 / 2003$ a sistemática do PIS e Cofins não cumulativos possibilita ao contribuinte o direito de apropriar créditos sobre determinados bens, insumos, custos e despesas. A legislação do PIS e Cofins determina a possibilidade de créditos no regime não cumulativo em relação:

Aos bens e serviços adquiridos de pessoa jurídica domiciliada no país; 
Aos custos e despesas incorridos, pagos ou creditados a pessoa jurídica domiciliada no país;

Aos bens e serviços adquiridos e aos custos e despesas incorridos;

* Em relação aos serviços e bens adquiridos no exterior a partir de 1 de maio de 2004 (art. 1 da IN SRF 457/2004).

Sendo assim os créditos admissíveis pelo regime da não cumulatividade são todos aqueles bens e serviços utilizados na produção. De acordo com as Leis n ${ }^{\text {os }}$ 10.637/2002 e 10.833/2003 créditos não autorizados, mas não impedidos pela lei, na comercialização/administração de mercadorias, que podem ser aproveitados pela empresa, porém sujeitos a questionamentos pelo fisco, mas com possibilidades de a empresa obter êxito em defesas administrativas e judiciais, por ferir o princípio da não cumulatividade.

No que tange os Créditos não autorizados, mas não impedidos pela Lei $n^{\underline{\text { os }}}$ 10.637/2002 e 10.833/2003, na comercialização/administração de mercadorias, que podem ser aproveitados pela empresa, porém sujeitos a questionamentos pelo fisco, mas com possibilidades de a empresa obter êxito em defesas administrativas e judiciais, por ferir o princípio da não cumulatividade. Ainda, o governo aumenta sua arrecadação em função da lei não esclarecer determinado assunto, para evitar tal aumento de carga tributária o contribuinte deve utilizar todos os artifícios legais e óbvios de interpretação da lei, tendo ciência do risco. Abaixo relacionamos os itens:

* Fornecimento de refeições aos funcionários;

* Combustíveis e lubrificantes;

Manutenção e reparo de veículos e equipamentos;

Manutenção e reparo de construções e benfeitorias;

Telefone;

Água;

- Serviços prestados por pessoas jurídicas de profissionais liberais (contadores, auditores, advogados, médicos, outros);

* Limpeza, vigilância;

Correios;

Transporte de funcionários; 


\section{Propaganda/Publicidade;}

Comissões pagas a empresas de representação comercial;

Despesas com viagens, hospedagens e alimentação;

Seguros;

Serviços de terceiros da administração/comercialização;

Despesas gerais, tais como: copa, cozinha, material de escritório, materiais de higiene e limpeza, entre outros.

Salienta se a importância de um bom embasamento legal para que todas essas despesas possam vir a ser possíveis créditos de aproveitamento do PIS e da Cofins. Conforme as Leis $\mathrm{n}^{\text {os }}$ 10.637/2002 e 10.833/2003 os créditos que tem sua utilização vedada pela legislação do PIS e da Cofins são:

* Mão de obra pessoa física (folha de pagamento, autônomo etc.);

* Bens e serviços adquiridos de pessoa jurídica domiciliada no exterior.

Com isso, conforme analisado no material publicado acerca dos créditos impedidos, os mesmos não apontam uma forma de fazer uso dos créditos mencionados anteriormente.

\section{METODOLOGIA}

O presente estudo que tem como objetivo analisar a apuração dos créditos dos tributos federais PIS e Cofins e seu aproveitamento para apuração de impostos em uma concessionária de automóveis, no sistema não cumulativo, apresenta-se como um estudo de caso e pactua na importância deste para a gestão financeira da empresa em análise.

Cientificamente, um estudo de caso consiste na realização de um profundo estudo do processo, produzindo assim um amplo e detalhado conhecimento, com o objetivo de perceber "como" e "por que" funcionam as "coisas", é um estudo empírico que busca compreender o fenômeno atual dentro do seu contexto de realidade (YIN, 2010).

No que tange a abordagem, a presente pesquisa apresenta-se como qualitativa, visando descrever e analisar acerca do objetivo estabelecido, além de verificar-se a 
interação do contexto abordado, compreendendo e classificando os processos dinâmicos do presente estudo. Ademais, como forma de complementaridade, a pesquisa possui caráter descritivo, que na ótica de Thomas, Nelson e Silverman (2007) buscam por meio da descrição das características de determinado processo e do estabelecimento de relações e variáveis, auxiliam na resolução de problemas, melhorando suas práticas.

Quanto aos objetivos da pesquisa, esta se apresenta como explicativa, na qual buscou-se identificar as causas para a ocorrência dos fenômenos, uma vez que aprofunda o conhecimento de uma dada realidade. Ainda, este estudo caracteriza-se, também, como bibliográfico porque se utilizou de fontes secundárias, possibilitando ao pesquisador a cobertura dos acontecimentos de forma mais amplos, bem como um maior entendimento do tema por meio de pesquisas realizadas em artigos e livros, disponibilizados em formato impresso e digital.

No que tange a pesquisa documental, buscar-se-á, primeiramente, um embasamento teórico sobre o assunto a ser abordado, através de uma pesquisa bibliográfica, bem como a análise dos documentos e dados cedidos pela empresa para a construção deste trabalho, além dos construídos a partir da observação realizada.

\section{RESULTADOS E DISCUSSÕES}

O presente estudo foi desenvolvido por meio da coleta de dados no setor de contabilidade de uma concessionária de veículos com atuação nacional, durante o primeiro semestre de 2016, os quais foram analisados os documentos fiscais e contábeis com o intuito de verificar quanto ao aproveitamento total dos créditos passíveis de utilização nos serviços, sendo estes destacados no decorrer dos resultados do presente artigo.

Assim, a empresa participante localiza-se na região central do Rio Grande do Sul, com atuação nacional e mais de 70 anos de mercado. Ainda, a administração da sociedade compete ao Diretor Executivo sendo por ele representada ativa e passivamente, judicial e extrajudicialmente, sendo assessorado pelos gerentes e supervisores das principais áreas. Atualmente, o Capital Social é de R \$ 8.500.000,00 (oito milhões e quinhentos mil reais), sendo esta tributada com base no Lucro Real. 


\subsection{Créditos tributários aproveitados}

O aproveitamento dos créditos do PIS e da Cofins, possibilita que as empresas paguem menos impostos, visto que, estas já possuem a obrigação de pagar sobre as vendas de peças, serviços e veículos usados. Apurando os créditos tributários de PIS e Cofins, a empresa compensa no valor dos débitos e paga o imposto devido efetivamente. Neste caso, a empresa apura os créditos de PIS e Cofins sobre os insumos que se consomem no processo de produção dos serviços de reparação automotiva (oficina mecânica, lavagem, funilaria e pintura).

Dessa forma, conforme abordado pela contadora responsável pela empresa segue abaixo os créditos já aproveitados pela empresa na apuração do cálculo de PIS e Cofins.

Compras para revenda: São as compras de mercadorias, para o estoque que serão revendidas. Como a empresa se enquadra no principio da não cumulatividade, a mesma se aproveita daquelas compras que são não monofásicos.

* Devoluções vendas tributadas: São aquelas entradas de devolução de itens não monofásicos. Esses itens que voltam para o estoque são o estorno do débito que teve a venda. Não é exatamente um crédito.

* Despesas Energia Elétrica: Despesa que dá direito a crédito porque é necessária para realização da atividade fim da empresa.

* Encargos Amortização de Prédios e Benfeitorias: Despesas das prédios e benfeitorias são créditos sobre os encargos de amortização de benfeitorias no prédio.

* Depreciação Máquinas: Despesas que são utilizadas para a atividade fim da empresa. Parcela das depreciações de máquinas e ferramentas utilizadas na realização dos serviços de oficina.

* Serviços contratados de Pessoa Jurídica: São aqueles serviços que são contratados de outra pessoa jurídica, já que a empresa não possui este serviço e que vão fazer parte do custo do serviço da empresa.

* Materiais insumos: Os materiais que são consumidos no processo de realização de serviços. E que se consome no processo de realização do serviço. 
Assim, percebe-se a importância do aproveitamento de créditos para empresa em foco, vindo este ao encontro do objetivo proposto nesta pesquisa que visa procurar aqueles créditos ainda não aproveitados e otimizar a apuração do PIS e da Cofins. Nas Tabelas 1 e 2, tem-se os créditos já aproveitados do PIS e da Cofins pela empresa no $1^{\circ}$ e $2^{\circ}$ trimestres de 2016, conforme citado anteriormente.

Tabela 1 - Cálculo dos créditos de PIS e Cofins já utilizados pela empresa $1^{\circ}$ trimestre

\begin{tabular}{|c|c|c|c|c|c|c|}
\hline \multirow{9}{*}{ 홓 } & Créditos & Créditos S & $\begin{array}{c}\text { \% passivel de } \\
\text { utilizacão }\end{array}$ & $\begin{array}{c}\text { Base Cálculo } \\
\text { Créditos }\end{array}$ & $\begin{array}{c}\text { PIS } \\
1.65 \%\end{array}$ & $\begin{array}{l}\text { Cofins } \\
7,60 \%\end{array}$ \\
\hline & Compras $\mathrm{p} /$ revenda & RS185,238,47 & $100 \%$ & R\$185,238,47 & R\$3.056.43 & R\$14.078,12 \\
\hline & Devoluçōes vendas - trib & RS4.812.50 & $100 \%$ & RS4.812.50 & R\$79.41 & $\mathrm{R} \$ 365.75$ \\
\hline & Despesa Energia Elétrica & $\mathrm{R} \$ 14.770,55$ & $97,32 \%$ & $\mathrm{R} \$ 14.374,70$ & RS237,18 & R\$1.092.48 \\
\hline & Enc. Prédios e & RS1.719.76 & $97,32 \%$ & $\mathrm{R} \$ 1.673 .67$ & $\mathrm{R} \$ 27,62$ & $\mathrm{R} \$ 127,20$ \\
\hline & Deprec. Máq. Equip. & RS2.540,13 & $97,32 \%$ & $\mathrm{R} \$ 2.472 .05$ & $\mathrm{R} \$ 40,79$ & $\mathrm{R} \$ 187,88$ \\
\hline & Serv. Contrat. PJ - & R\$9.571.00 & $100 \%$ & $\mathrm{R} \$ 9.571 .00$ & RS 157.92 & R\$727.40 \\
\hline & Materiais - Insumos & R\$19.395.28 & $100 \%$ & R\$19.395,28 & RS320,02 & $\mathrm{RS} 1.474 .04$ \\
\hline & Total de Créditos & RS238.047,69 & & RS237.537,67 & RS3.919,37 & RS18.052.86 \\
\hline \multirow{9}{*}{$\frac{\varepsilon}{\frac{\varepsilon}{v}}$} & Créditos & Créditos $\mathrm{S}$ & $\begin{array}{c}\% \text { passivel de } \\
\text { utilizacão }\end{array}$ & $\begin{array}{c}\text { Base Cálculo } \\
\text { Créditos } \\
\end{array}$ & \begin{tabular}{|c|} 
PIS \\
$1,65 \%$ \\
\end{tabular} & $\begin{array}{l}\text { Cofins } \\
7,60 \% \\
\end{array}$ \\
\hline & Compras $\mathrm{p} /$ revenda & RS109.050,96 & $100 \%$ & R\$109.050,96 & R\$1.799,34 & R\$8.287.87 \\
\hline & Devoluções vendas - trib & $\mathrm{R} \$ 3.954,47$ & $100 \%$ & $\mathrm{R} \$ 3.954,47$ & $\mathrm{R} \$ 65,25$ & $\mathrm{R} \$ 300,54$ \\
\hline & Despesa Energia Elétrica & R\$15.752,84 & $96,70 \%$ & R\$15.233,00 & RS251,34 & R\$1.157.71 \\
\hline & Enc. Prédios e & RS1.719,76 & $96,70 \%$ & R\$1.663,01 & $\mathrm{R} \$ 27,44$ & $\mathrm{R} \$ 126,39$ \\
\hline & Deprec. Máq. Equip. & RS2.540,13 & $96,70 \%$ & $\mathrm{R} \$ 2.456,31$ & $\mathrm{R} \$ 40,53$ & $\mathrm{R} \$ 186,68$ \\
\hline & Serv. Contrat. PJ - & RS4.410,99 & $100 \%$ & R\$4.410,99 & $\mathrm{R} \$ 72,78$ & $\mathrm{R} \$ 335,24$ \\
\hline & Materiais - Insumos & $\mathrm{R} \$ 21.811,94$ & $100 \%$ & R\$21.811,94 & R\$359,90 & R\$1.657,71 \\
\hline & Total de Créditos & RS159.241,09 & & RS158.580,67 & RS2.616,58 & RS12.052.13 \\
\hline \multirow{9}{*}{ 할 } & Créditos & Créditos S & $\begin{array}{c}\% \text { passivel de } \\
\text { utilizacão }\end{array}$ & $\begin{array}{c}\text { Base Cálculo } \\
\text { Créditos }\end{array}$ & \begin{tabular}{|c|} 
PIS \\
$1,65 \%$ \\
\end{tabular} & $\begin{array}{l}\text { Cofins } \\
7,60 \% \\
\end{array}$ \\
\hline & Compras $\mathrm{p} /$ revenda & RS211.149,73 & $100 \%$ & R\$211.149,73 & R\$3.483,97 & R\$16.047,38 \\
\hline & Devoluções vendas - trib & RS2.700,99 & $100 \%$ & $\mathrm{R} \$ 2.700,99$ & $\mathrm{R} \$ 44,57$ & $\mathrm{R} \$ 205,28$ \\
\hline & Despesa Energia Elétrica & R\$14.347.47 & $96,09 \%$ & R\$13.786.48 & RS227,48 & R\$1.047,77 \\
\hline & Enc. Prédios e & RS1.719,76 & $96,09 \%$ & $\mathrm{R} \$ 1.652,52$ & $\mathrm{R} \$ 27,27$ & $\mathrm{R} \$ 125,59$ \\
\hline & Deprec. Máq. Equip. & RS2.540.13 & $96,09 \%$ & $\mathrm{R} \$ 2.440,81$ & $\mathrm{R} \$ 40,27$ & R\$185,50 \\
\hline & Serv. Contrat. PJ - & R\$7.733,00 & $100 \%$ & R\$7.733,00 & RS127,59 & $\mathrm{R} \$ 587,71$ \\
\hline & Materiais - Insumos & $\mathrm{R} \$ 30.288,69$ & $100 \%$ & $\mathrm{R} \$ 30.288,69$ & RS499,76 & $\mathrm{R} \$ 2.301,94$ \\
\hline & Total de Créditos & RS270.479,77 & & RS269.752.22 & RS4.450,91 & RS20.501.17 \\
\hline
\end{tabular}

Fonte: Dados da pesquisa

Nota-se nas tabelas apresentadas que houve uma variação mensal nas compras para revenda, pois, sendo estas mercadorias que serão revendidas, então não existe a necessidade de todos os meses ocorrerem as mesmas compras. A empresa junto com seu gerente de estoque vê o que tem necessidade de compra e reabastece o estoque desta forma.

As devoluções de vendas tributadas acontecem conforme os imprevistos que surgem ao longo de cada mês na empresa. Os créditos se alteram dependendo a quantidade de devoluções realizadas. No que tange a energia elétrica nota-se que no primeiro trimestre do ano os valores são mais elevados devido ao calor. 
$\mathrm{Na}$ conta encargos prédios e benfeitorias, segue se um valor base, que se mantém em janeiro e meses subsequentes, devido a não realização de obras nas estruturas físicas da empresa. Por fim, observa-se que os serviços contratados de pessoa jurídica, que na Tabela 1 demonstra que o mês de janeiro foi o mês que mais teve solicitação de serviço, pois, entende-se que devido ao advento das férias a procura pelos serviços aumenta, possibilitando assim um maior aproveitamento nesta conta. No entanto na conta materiais insumos o mês que mais gerou créditos foi o mês de março.

Conforme a legislação tem se a necessidade de fazer uma proporcionalidade das receitas, pois, nem todas fazem parte do regime não cumulativo. É o caso da despesa com energia elétrica, depreciação das máquinas e equipamentos e encargos com prédios e benfeitorias. Na tabela 2, tem se a continuidade do cálculo dos créditos conforme averiguado na tabela de controle gerencial utilizada pelos gestores da empresa para apuração do PIS e da Cofins, para o segundo trimestre de 2017.

Tabela 2 - Cálculo dos créditos de PIS e Cofins já utilizados pela empresa $2^{\circ}$ trimestre

\begin{tabular}{|c|c|c|c|c|c|c|}
\hline \multirow{9}{*}{$\overline{5}$} & Créditos & Créditos $\$$ & $\begin{array}{l}\text { \% passivel de } \\
\text { utilização }\end{array}$ & $\begin{array}{c}\text { Base Cálculo } \\
\text { Créditos }\end{array}$ & $\begin{array}{c}\text { PIS } \\
1,65 \%\end{array}$ & $\begin{array}{l}\text { Cofins } \\
7,60 \%\end{array}$ \\
\hline & Compras p/revenda & $\mathrm{R} \$ 131.647,12$ & $100 \%$ & $\mathrm{R} \$ 131.647,12$ & $\mathrm{R} \$ 2.172,18$ & $\mathrm{R} \$ 10.005,18$ \\
\hline & Devoluções vendas - trib & $\mathrm{R} \$ 1.706,18$ & $100 \%$ & $\mathrm{R} \$ 1.706,18$ & $\mathrm{R} \$ 28,15$ & $\mathrm{R} \$ 129,67$ \\
\hline & Despesa Energia Elétrica & $\mathrm{R} \$ 13.055,21$ & $97,49 \%$ & $\mathrm{R} \$ 12.727,52$ & $\mathrm{R} \$ 210,00$ & $\mathrm{R} \$ 967,29$ \\
\hline & Enc. Prédios e & $\mathrm{R} \$ 1.719,16$ & $97,49 \%$ & $\mathrm{R} \$ 1.676,01$ & $\mathrm{R} \$ 27,65$ & $\mathrm{R} \$ 127,38$ \\
\hline & Deprec. Máq. Equip. & $\mathrm{R} \$ 2.544,21$ & $97,49 \%$ & $\mathrm{R} \$ 2.480,35$ & $\mathrm{R} \$ 40,93$ & $\mathrm{R} \$ 188,51$ \\
\hline & Serv. Contrat. PJ - & $R \$ 16.235,00$ & $100 \%$ & $R \$ 16.235,00$ & $\mathrm{R} \$ 267,88$ & $\mathrm{R} \$ 1.233,86$ \\
\hline & Materiais - Insumos & $\mathrm{R} \$ 8.976,57$ & $100 \%$ & $\mathrm{R} \$ 8.976,57$ & $\mathrm{R} \$ 148,11$ & $\mathrm{R} \$ 682,22$ \\
\hline & Total de Créditos & R\$175.883,45 & & R\$175.448,75 & R\$2.894,90 & R\$13.334,11 \\
\hline \multirow{9}{*}{ 욜 } & Créditos & Créditos \$ & $\begin{array}{c}\% \text { passivel de } \\
\text { utilização }\end{array}$ & $\begin{array}{c}\text { Base Cálculo } \\
\text { Créditos }\end{array}$ & $\begin{array}{c}\text { PIS } \\
1,65 \%\end{array}$ & $\begin{array}{l}\text { Cofins } \\
7,60 \% \\
\end{array}$ \\
\hline & Compras $\mathrm{p} /$ revenda & $\mathrm{R} \$ 237.609,27$ & $100 \%$ & $\mathrm{R} \$ 237.609,27$ & $\mathrm{R} \$ 3.920,55$ & $\mathrm{R} \$ 18.058,30$ \\
\hline & Devoluções vendas - trib & $\mathrm{R} \$ 19.311,13$ & $100 \%$ & $\mathrm{R} \$ 19.311,13$ & $\mathrm{R} \$ 318,63$ & $\mathrm{R} \$ 1.467,65$ \\
\hline & Despesa Energia Elétrica & $R \$ 12.616,02$ & $97,61 \%$ & $\mathrm{R} \$ 12.314,50$ & $\mathrm{R} \$ 203,19$ & $\mathrm{R} \$ 935,90$ \\
\hline & Enc. Prédios e & $\mathrm{R} \$ 1.719,76$ & $97,61 \%$ & $\mathrm{R} \$ 1.678,66$ & $\mathrm{R} \$ 27,70$ & $\mathrm{R} \$ 127,58$ \\
\hline & Deprec. Máq. Equip. & $\mathrm{R} \$ 2.562,24$ & $97,61 \%$ & $\mathrm{R} \$ 2.501,00$ & $\mathrm{R} \$ 41,27$ & $\mathrm{R} \$ 190,08$ \\
\hline & Serv. Contrat. PJ - & $R \$ 13.965,00$ & $100 \%$ & $R \$ 13.965,00$ & $\mathrm{R} \$ 230,42$ & $\mathrm{R} \$ 1.061,34$ \\
\hline & Materiais - Insumos & $\mathrm{R} \$ 22.249,63$ & $100 \%$ & $\mathrm{R} \$ 22.249,63$ & $\mathrm{R} \$ 367,12$ & $\mathrm{R} \$ 1.690,97$ \\
\hline & Total de Créditos & R\$310.033,05 & & R\$309.629,19 & R\$5.108,88 & R\$23.531,82 \\
\hline \multirow{9}{*}{ 큋 } & Créditos & Créditos $\$$ & $\begin{array}{c}\% \text { passivel de } \\
\text { utilização }\end{array}$ & $\begin{array}{c}\text { Base Cálculo } \\
\text { Créditos }\end{array}$ & $\begin{array}{c}\text { PIS } \\
1,65 \% \\
\end{array}$ & $\begin{array}{l}\text { Cofins } \\
7,60 \% \\
\end{array}$ \\
\hline & Compras p/revenda & $\mathrm{R} \$ 198.976,08$ & $100 \%$ & $\mathrm{R} \$ 198.976,08$ & $\mathrm{R} \$ 3.283,11$ & $\mathrm{R} \$ 15.122,18$ \\
\hline & Devoluções vendas - trib & $\mathrm{R} \$ 12.776,74$ & $100 \%$ & $\mathrm{R} \$ 12.776,74$ & $\mathrm{R} \$ 210,82$ & $\mathrm{R} \$ 971,03$ \\
\hline & Despesa Energia Elétrica & $\mathrm{R} \$ 11.585,25$ & $97,09 \%$ & $\mathrm{R} \$ 11.248,12$ & $\mathrm{R} \$ 185,59$ & $\mathrm{R} \$ 854,86$ \\
\hline & Enc. Prédios e & $\mathrm{R} \$ 1.719 .76$ & $97,09 \%$ & $\mathrm{R} \$ 1.669,71$ & $\mathrm{R} \$ 27,55$ & $\mathrm{R} \$ 126,90$ \\
\hline & Deprec. Máq. Equip. & $\mathrm{R} \$ 2.683,54$ & $97,09 \%$ & $\mathrm{R} \$ 2.605,45$ & $\mathrm{R} \$ 42,99$ & $\mathrm{R} \$ 198,01$ \\
\hline & Serv. Contrat. PJ - & $R \$ 8.175,00$ & $100 \%$ & $\mathrm{R} \$ 8.175,00$ & $\mathrm{R} \$ 134,89$ & $R \$ 621,30$ \\
\hline & Materiais - Insumos & $\mathrm{R} \$ 11.916,38$ & $100 \%$ & $\mathrm{R} \$ 11.916 .38$ & $\mathrm{R} \$ 196,62$ & $\mathrm{R} \$ 905,64$ \\
\hline & Total de Créditos & R\$247.832,75 & & R\$247.367,48 & R\$4.081,56 & R\$18.799,93 \\
\hline
\end{tabular}

Fonte: Dados da pesquisa

Na Tabela 2, têm-se os créditos passiveis de utilização, os quais são: compras 
para revenda, devoluções de vendas tributadas, despesa de energia elétrica, encargos prédios e benfeitorias, depreciações de máquinas e equipamentos, serviços contratados de pessoa jurídica e materiais insumo com seus devidos valores mensais.

Em consenso ao exposto, levando em consideração a fala da contadora da empresa em análise, "a apuração dos créditos de PIS e Cofins evitam que a empresa pague imposto a maior, pois, tem a obrigação de pagar sobre as vendas de peças, serviços e veículos usados. Apurando os créditos a empresa compensa no valor dos débitos e paga o imposto devido efetivamente".

Dessa forma, conforme verificado na empresa, o mapeamento dos insumos que poderão ser creditados é feito no momento do lançamento da nota fiscal de aquisição dos mesmos. A empresa possui contas especificas no seu plano de contas contábil que segregam os materiais adquiridos para insumos (que serão consumidos no processo de realização dos serviços) e os serviços contratados de outras pessoas jurídicas que farão parte do custo dos serviços vendidos. Essas contas são utilizadas para a apuração do valor dos insumos que poderão gerar créditos de PIS e Cofins.

Quanto ao aproveitamento dos créditos do PIS e da Cofins em sua totalidade, percebe-se que esta resulta em uma economia tributária advinda da compensação do valor apurado de créditos com o valor apurado de impostos a pagar, pois, sem a apuração da totalidade de créditos a empresa paga mais PIS e Cofins.

\subsection{Mapeamento dos créditos não utilizados}

A economia tributária é resultante da compensação dos valores ainda não aproveitados de créditos com o valor apurado de impostos a pagar, pois, sem esta apuração da totalidade de créditos a empresa paga mais PIS e Cofins, conforme pode-se verificar nas Tabelas 3 - primeiro trimestre de 2017 - e 4 - segundo trimestre de 2017.

Dessa forma, a classificação das despesas é feita no momento do lançamento da nota fiscal de aquisição dos insumos, uma vez que a empresa possui contas específicas no seu plano de contas contábil que segregam os materiais adquiridos para insumos (que serão consumidos no processo de realização dos serviços) e os serviços contratados de outras pessoas jurídicas que farão parte do custo dos serviços vendidos. Essas contas 
são utilizadas para a apuração do valor dos insumos que poderão gerar créditos de PIS e Cofins.

Tabela 3 - Cálculo dos créditos de PIS e Cofins ainda não utilizados pela empresa $1^{\circ}$ trimestre

\begin{tabular}{|c|c|c|c|c|c|}
\hline Créditos & Créditos \$ & $\begin{array}{c}\text { \% passiv el de } \\
\text { utilização }\end{array}$ & $\begin{array}{c}\text { Base Cálculo } \\
\text { Créditos }\end{array}$ & \begin{tabular}{|c|} 
PIS \\
$1,65 \%$
\end{tabular} & $\begin{array}{l}\text { Cofins } \\
7,60 \% \\
\end{array}$ \\
\hline Remuneração vendedores & RS49.926,09 & $100,00 \%$ & RS49.926.09 & RS823,78 & $\overline{R S 3.794,38}$ \\
\hline Remuner ação dirigentes & RS5.000,00 & $100,00 \%$ & RS5.000,00 & RS 82,50 & RS380,00 \\
\hline Salários das chefias & RS36.878,58 & $100,00 \%$ & R\$36.878,58 & RS608,50 & RS2.802,77 \\
\hline Salários demais empregados & RS61.176,41 & $100,00 \%$ & RS61.176,41 & RS $1.009,41$ & $\overline{R S 4.649,41}$ \\
\hline Despesas cférias e $13^{\circ}$ sal. & RS55.528,75 & $100,00 \%$ & R\$55.528,75 & RS916,22 & RS4.220,19 \\
\hline Assistência Médica & RS7.295,73 & $100,00 \%$ & RS7.295,73 & RS120,38 & RS554,48 \\
\hline \begin{tabular}{|l|} 
Vale Transporte \\
\end{tabular} & RS1.074,92 & $100,00 \%$ & RS1.074,92 & RS 17,74 & RS\& 1,69 \\
\hline Prog. Alim. Ao Trabalhador & RS25.409,10 & $100,00 \%$ & R\$25.409,10 & RS419,25 & $\overline{R S 1.931,09}$ \\
\hline Demais benef. à empregados & RS60,70 & $100,00 \%$ & RS 60,70 & $\mathrm{R} \$ 1,00$ & RS 4,61 \\
\hline Encar gos sociais - FGTS & RS21.847,95 & $100,00 \%$ & R\$2 $1.847,95$ & RS360,49 & $\overline{R S 1.660,44}$ \\
\hline Encar gos sociais - INSS & RS56.682,82 & $100,00 \%$ & R\$56.682,82 & RS935,27 & RS4.307,89 \\
\hline Encar gos sociais - outros & R\$1.395,59 & $100,00 \%$ & RS1.395,59 & RS23,03 & RS106,06 \\
\hline Impostos e taxas - Im óveis & RS971,86 & $100,00 \%$ & R\$971,86 & RS16,04 & R\$73,86 \\
\hline Txs - Fed. Est. e Municipais & R\$333,05 & $100,00 \%$ & R\$333,05 & R\$5,50 & R\$25,31 \\
\hline Imposto sindical & RS6.827,61 & $100,00 \%$ & RS6.827,61 & RS1 12,66 & RS518,90 \\
\hline Outros impostos e tax as & RS1.152,25 & $100,00 \%$ & RS $1.152,25$ & RS 19,01 & R\$87,57 \\
\hline Total de Créditos & R\$235.071,18 & $100,00 \%$ & R\$235.071,18 & R\$3.878,67 & R\$17.865,41 \\
\hline Créditos & Créditos\$ & $\begin{array}{c}\text { \%passiv el de } \\
\text { utilização }\end{array}$ & $\begin{array}{c}\text { Base Cálculo } \\
\text { Créditos }\end{array}$ & \begin{tabular}{|c|} 
PIS \\
$1,65 \%$
\end{tabular} & $\begin{array}{l}\text { Cofins } \\
7,60 \% \\
\end{array}$ \\
\hline Remuneração vendedores & RS28.895,91 & $100,00 \%$ & RS28.895,91 & RS4 76,78 & RS2.196,09 \\
\hline Remuner ação dirigentes & RS5.000,00 & $100,00 \%$ & RS5.000,00 & RS82,50 & RS380,00 \\
\hline Salários das chefias & RS28.933,47 & $100,00 \%$ & R\$28.933,47 & RS477,40 & $\overline{R S 2.198,94}$ \\
\hline Salários demais empregados & RS63.345,53 & $100,00 \%$ & RS63.345,53 & RS $1.045,20$ & RS4.814,26 \\
\hline Despesas cférias e $13^{\circ}$ sal. & RS55.680,62 & $100,00 \%$ & R\$55.680,62 & RS918,73 & RS4.231,73 \\
\hline Assistência Médica & RSS.174,89 & $100,00 \%$ & RSS.174,89 & RS134,89 & RS621,29 \\
\hline Vale Transporte & RS967,15 & $100,00 \%$ & RS967,15 & RS 15,96 & $R \$ 73,50$ \\
\hline Prog. Alim. Ao Trabalhador & RS16.876,80 & $100,00 \%$ & RS16.876,80 & R\$278,47 & RS1.282,64 \\
\hline Dem ais benef. à empregados & $\mathrm{R} \$ 1.370,00$ & $100,00 \%$ & RS $1.370,00$ & $\mathrm{R} \$ 22,61$ & RS 104,12 \\
\hline Encar gos sociais - FGTS & RS19.658,11 & $100,00 \%$ & RS19.658,11 & RS324,36 & $\overline{R S 1.494,02}$ \\
\hline Encar gos sociais - INSS & RS48.198,07 & $100,00 \%$ & RS48.198,07 & RS795,27 & R\$3.663,05 \\
\hline Encar gos sociais - outros & R\$1.236,36 & $100,00 \%$ & RS1.236,36 & RS20,40 & R\$93,96 \\
\hline Impostos e taxas - Im óveis & RS971,87 & $100,00 \%$ & RS971,87 & RS16,04 & $R \$ 73,86$ \\
\hline Txs - Fed. Est. e Municipais & RS333,05 & $100,00 \%$ & R\$333,05 & $\mathrm{R} \$ 5,50$ & $\bar{R} \$ 25,31$ \\
\hline Imposto sindical & RSO 00 & $100,00 \%$ & $\mathrm{R} S 0,00$ & $\mathrm{R} S 0,00$ & $\mathrm{RSO}, 00$ \\
\hline Outros impostos e tax as & RS468,07 & $100,00 \%$ & RS468,07 & $\mathrm{R} S 7,72$ & RS35,57 \\
\hline Total de Créditos & R\$199.200,40 & $100,00 \%$ & R\$199.200,40 & R\$3.286,81 & R\$15.139,23 \\
\hline Créditos & Créditos \$ & $\begin{array}{c}\text { \% passiv el de } \\
\text { utilização }\end{array}$ & $\begin{array}{c}\text { Base Cálculo } \\
\text { Créditos }\end{array}$ & \begin{tabular}{|c|} 
PIS \\
$1,65 \%$
\end{tabular} & $\begin{array}{l}\text { Cofins } \\
7,60 \% \\
\end{array}$ \\
\hline Remuneração vendedores & RS $40.776,30$ & $100,00 \%$ & RS40.776,30 & RS672,81 & RS3.099,00 \\
\hline Remuneração dirigentes & RS5.000,00 & $100,00 \%$ & RS5.000,00 & RS 82,50 & RS380,00 \\
\hline Salários das chefias & RS36.306,81 & $100,00 \%$ & RS36.306,81 & RS599,06 & RS2.759,32 \\
\hline Salários demais empregados & RS61.173,77 & $100,00 \%$ & RS61.173,77 & RS $1.009,37$ & $\mathrm{R} \$ 4.649,21$ \\
\hline Despesas cfférias e $13^{\circ}$ sal. & RS58.392,27 & $100,00 \%$ & R\$58.392,27 & RS963,47 & RS4.437,81 \\
\hline \begin{tabular}{|l|} 
Assistência Médica \\
\end{tabular} & RS7.992,70 & $100,00 \%$ & RS7.992,70 & RS131,88 & RS 607,45 \\
\hline Vale Transporte & RS1.399,93 & $100,00 \%$ & RS1.399,93 & RS23,10 & RS 106,39 \\
\hline Prog. Alim. Ao Trabalhador & RS17.573,50 & $100,00 \%$ & R\$17.573,50 & R\$289,96 & $\bar{R} \$ 1.335,59$ \\
\hline Demais benef. à empregados & R\$2.077,17 & $100,00 \%$ & RS2.077,17 & RS34,27 & RS 157,86 \\
\hline Encar gos sociais - FGTS & RS15.316,43 & $100,00 \%$ & R\$15.316,43 & RS252,72 & RS1.164,05 \\
\hline Encargos sociais - INSS & RS53.933,62 & $100,00 \%$ & R\$53.933,62 & RS8 89,90 & $\overline{R S 4.098,96}$ \\
\hline Encar gos sociais - outr os & RSO, 00 & $100,00 \%$ & RSO 0,00 & RSO,00 & RS 0,00 \\
\hline Impostos e taxas - Im óveis & RS995,79 & $100,00 \%$ & R\$995,79 & RS16,43 & R\$75,68 \\
\hline Txs - Fed. Est. e Municipais & R\$333,05 & $100,00 \%$ & R\$333,05 & R\$5,50 & R $\$ 25,31$ \\
\hline Imposto sindical & RSO, 00 & $100,00 \%$ & RSO,00 & RSO,00 & RS 0,00 \\
\hline Outros impostos e tax as & RS14.217,62 & $100,00 \%$ & R\$14.217,62 & R\$234,59 & RS1.080,54 \\
\hline Total de Créditos & R\$233.440,27 & $100,00 \%$ & R\$233.440,27 & R\$3.851,76 & R\$17.741,46 \\
\hline
\end{tabular}

Fonte: Dados da pesquisa 
Tabela 4 - Cálculo dos créditos de PIS e Cofins ainda não utilizados pela empresa $2^{\circ}$ trimestre

\begin{tabular}{|c|c|c|c|c|c|c|}
\hline & Créditos & Créditos\$ & $\begin{array}{c}\% \text { passiv el de } \\
\text { utilização }\end{array}$ & $\begin{array}{l}\text { Base Cálculo } \\
\text { Créditos }\end{array}$ & $\begin{array}{c}\text { PIS } \\
1,65 \%\end{array}$ & $\begin{array}{l}\text { Cofins } \\
7,60 \%\end{array}$ \\
\hline & Remuneração vendedores & RS34.340.39 & $100,00 \%$ & R\$34.340,39 & RS566,62 & R\$2.609,87 \\
\hline & Remuner ação dirigentes & RS5.000,00 & $100,00 \%$ & RS5.000,00 & RS 82,50 & RS380,00 \\
\hline & Salários das chefias & RS39.523.69 & $100,00 \%$ & R\$39.523,69 & RS652,14 & R\$3.003,80 \\
\hline & Salários dem ais empregados & RS68.266.38 & $100,00 \%$ & RS68.266.38 & RS $1.126,40$ & RS5.188,24 \\
\hline & Despesas cférias e $13^{\circ}$ sal. & RS5 $5.513,43$ & $100,00 \%$ & RS54.513,43 & R\$899,47 & RS4.143,02 \\
\hline & Assistência Médica & RS6.363,66 & $100,00 \%$ & RS6.363,66 & $\mathrm{R} \$ 105,00$ & RS 483,64 \\
\hline & Vale Transporte & RS1.194,89 & $100,00 \%$ & R\$1.194,89 & RS 19,72 & R\$90,81 \\
\hline & Prog. Alim. Ao Trabalhador & RS23.318,45 & $100,00 \%$ & R\$23.318,45 & R\$384,75 & RS1.772,20 \\
\hline & Demais benef. à empregados & RS1.182,27 & $100,00 \%$ & R\$1.182,27 & RS19,51 & RS89,85 \\
\hline & Encar gos sociais - FGTS & RS17.790,45 & $100,00 \%$ & R\$17.790,45 & R\$293,54 & $\mathrm{R} \$ 1.352,07$ \\
\hline & Encar gos sociais - INSS & RS54.396,43 & $100,00 \%$ & R\$54.396,43 & R\$897,54 & RS4.134,13 \\
\hline & Encargos sociais - outros & RS508,98 & $100,00 \%$ & RS508,98 & R\$8,40 & $\mathrm{R} \$ 38,68$ \\
\hline & Impostos e taxas - Im óveis & RS971,87 & $100,00 \%$ & RS971,87 & RS 16,04 & $\bar{R} \$ 73,86$ \\
\hline & Txs - Fed. Est. e Municipais & RS547,33 & $100,00 \%$ & RS547,33 & RS9,03 & $\overline{\mathrm{R} S 41,60}$ \\
\hline & Imposto sindical & RSO,00 & $100,00 \%$ & RS 0,00 & RSO,00 & RS0,00 \\
\hline & Outros impostos e tax as & $\mathrm{RS} 1.280,52$ & $100,00 \%$ & $\mathrm{R} \$ 1.280,52$ & RS21,13 & $\overline{\mathrm{R} \$ 97,32}$ \\
\hline & Total de Créditos & R\$226.242,86 & $100,00 \%$ & R\$226.242,86 & R\$3.733,01 & R\$17.194,46 \\
\hline \multirow{36}{*}{ 욜 } & Créditos & Créditos\$ & $\begin{array}{c}\text { \% passiv el de } \\
\text { utilização }\end{array}$ & $\begin{array}{c}\text { Base Cálculo } \\
\text { Créditos }\end{array}$ & \begin{tabular}{|c|} 
PIS \\
$1,65 \%$
\end{tabular} & $\begin{array}{l}\text { Cofins } \\
7,60 \%\end{array}$ \\
\hline & Remuner ação vendedores & R\$30.397,37 & $100,00 \%$ & R\$30.397,37 & R\$501,56 & $\mathrm{R} \$ 2.310,20$ \\
\hline & Remuner ação dirigentes & RS5.000,00 & $100,00 \%$ & R\$5.000,00 & RS 82,50 & R\$380,00 \\
\hline & Salários das chefias & R\$39.222,02 & $100,00 \%$ & R\$39.222,02 & RS647,16 & R\$2.980,87 \\
\hline & Salários demais empregados & RS68.172,39 & $100,00 \%$ & R\$68.172,39 & RS1.124,84 & $\mathrm{R} \$ 5.181,10$ \\
\hline & Despesas cfférias e $13^{\circ} \mathrm{sal}$. & RS71.306,37 & $100,00 \%$ & R\$71.306,37 & RS1.176,56 & $\mathrm{R} \$ 5.419,28$ \\
\hline & Assistência Médica & RS7.951,56 & $100,00 \%$ & R\$7.951,56 & R\$131,20 & RS 604,32 \\
\hline & Vale Transporte & RS $1.327,97$ & $100,00 \%$ & RS1.327,97 & RS21,91 & RS 100,93 \\
\hline & Prog. Alim. Ao Trabalhador & R\$2 $1.399,35$ & $100,00 \%$ & R\$21.399,35 & R\$353,09 & $\mathrm{R} \$ 1.626,35$ \\
\hline & Demais benef. à empregados & RS1.825,36 & $100,00 \%$ & R\$1.825,36 & RS30,12 & RS138,73 \\
\hline & Encar gos sociais - FGTS & RS20.573,18 & $100,00 \%$ & R\$20.573,18 & R\$339,46 & R\$1.563,56 \\
\hline & Encar gos sociais - INSS & RS55.614,76 & $100,00 \%$ & RS55.614,76 & R\$917,64 & RS4.226,72 \\
\hline & Encargos sociais - outros & RS1.130,71 & $00 \%$ & R\$1.130,71 & RS 18,66 & $\$ 85,93$ \\
\hline & Impostos e taxas - Im óveis & RS $1.052,67$ & $00 \%$ & $\mathrm{R} \$ 1.052,67$ & RS17,37 & RS 80,00 \\
\hline & Txs - Fed. Est. e Municipais & RS343,19 & $00 \%$ & R\$343,19 & $\mathrm{R} S 5,66$ & RS26,08 \\
\hline & Imposto sindical & $\mathrm{RS} 0,00$ & $00 \%$ & RSO 0,00 & RSO, 00 & $\mathrm{RSO}, 00$ \\
\hline & Outros impostos e tax as & RS 166,88 & $00 \%$ & RS166,88 & $\mathrm{R} S 2,75$ & RS12,68 \\
\hline & Total de Créditos & R $\$ 235.664,38$ & $100,00 \%$ & R\$235.664,38 & R\$3.888,46 & R\$17.910,49 \\
\hline & Créditos & Créditos\$ & $\begin{array}{c}\text { \% passiv el de } \\
\text { utilização }\end{array}$ & $\begin{array}{c}\text { Base Cálculo } \\
\text { Créditos }\end{array}$ & $\begin{array}{c}\text { PIS } \\
1,65 \%\end{array}$ & $\begin{array}{l}\text { Cofins } \\
7,60 \%\end{array}$ \\
\hline & Remuneração vendedores & RS38.133,52 & $100,00 \%$ & RS38.133,52 & RS629,20 & R\$2.898,15 \\
\hline & Remuner ação dirigentes & RS5.000,00 & $100,00 \%$ & R\$5.000,00 & RS 82,50 & RS380,00 \\
\hline & Salários das chefias & RS38.259,46 & $100,00 \%$ & R\$38.259,46 & RS631,28 & R\$2.907,72 \\
\hline & Salários demais empregados & RS66.595,10 & $100,00 \%$ & RS66.595,10 & RS1.098,82 & RS5.061,23 \\
\hline & Despesas cfférias e $13^{\circ}$ sal. & RS55.393,17 & $100,00 \%$ & R\$55.393,17 & R\$913,99 & $\overline{R S 4.209,88}$ \\
\hline & Assistência Médica & RS $8.400,85$ & $100,00 \%$ & RS8.400,85 & R\$138,61 & RS638,46 \\
\hline & Vale Transporte & RS1.833,12 & $100,00 \%$ & R\$1.833,12 & RS30,25 & $\overline{R S 139,32}$ \\
\hline & Prog. Alim. Ao Trabalhador & RS20.943,45 & $100,00 \%$ & R\$20.943,45 & R\$345,57 & $\mathrm{R} \$ 1.591,70$ \\
\hline & Demais benef. à empregados & RS1.495,94 & $100,00 \%$ & R\$1.495,94 & RS24,68 & RS113,69 \\
\hline & Encar gos sociais - FGTS & RS19.103,15 & $100,00 \%$ & R\$19.103,15 & R\$315,20 & R\$1.451,84 \\
\hline & Encargos sociais - INSS & RS58.208,72 & $100,00 \%$ & R\$58.208,72 & R\$960,44 & R\$4.423,86 \\
\hline & Encar gos sociais - outr os & RS520,11 & $100,00 \%$ & $\mathrm{RS} 520,11$ & RS8,58 & $\mathrm{R} \$ 39,53$ \\
\hline & Impostos e taxas - Imóveis & RS971,87 & $100,00 \%$ & RS971,87 & RS16,04 & $\bar{R} \$ 73,86$ \\
\hline & Txs - Fed. Est. e Municipais & RS343,19 & $100,00 \%$ & $\mathrm{R} \$ 343,19$ & $\mathrm{R} \$ 5,66$ & R\$26,08 \\
\hline & Imposto sindical & RSO,00 & $100,00 \%$ & $\mathrm{RS} 0,00$ & RSO,00 & $\mathrm{RS} 0,00$ \\
\hline & Outros impostos e tax as & RS $1.148,10$ & $100,00 \%$ & RS1.148,10 & RS18,94 & R\$87,26 \\
\hline & Total de Créditos & R\$225.472,80 & $100,00 \%$ & R\$225.472,80 & R\$3.720,30 & R\$17.135,93 \\
\hline
\end{tabular}

Fonte: Dados da pesquisa 
Conforme pode-se verificar nas Tabelas 3 - primeiro trimestre de 2017 - e 4 segundo trimestre de 2017, vários créditos não são utilizados pela empresa. A maioria desses se encontra na oficina mecânica e funilaria. E é perceptível a mudança que geraria se a empresa já viesse fazendo o aproveitamento dos créditos.

\subsection{Comparação dos dados levantados}

Diante todas informações coletadas ao longo deste estudo, pode-se assim comparar o que a empresa esta deixando de aproveitar com os créditos do PIS e da Cofins.

Na tabela 5, tem-se de forma clara o faturamento da empresa nos últimos 6 meses, e os valores apurados do PIS e da Cofins neste período com suas devidas alíquotas seguindo o Principio da não cumulatividade, que estabelece alíquota de 7,60\% para Cofins e 1,65\% para o PIS. Percebe-se também, que estes valores são expressivos, necessitando dessa forma que a empresa controle e tente aproveitar o máximo de créditos possíveis, diminuindo assim, o gasto com estes tributos.

Tabela 5 - Cálculo do PIS e da Cofins sobre o Faturamento

\begin{tabular}{|c|c|c|c|c|c|c|c|c|c|c|c|c|}
\hline Meses & \multicolumn{2}{|r|}{ Janeiro } & \multicolumn{2}{|c|}{ Fevereiro } & \multicolumn{2}{|r|}{ Marco } & \multicolumn{2}{|r|}{ Abril } & \multicolumn{2}{|r|}{ Maio } & \multicolumn{2}{|r|}{ Junho } \\
\hline Faturamento & $\mathrm{RS}$ & $4.940 .713,15$ & RS & $4.017 .400,91$ & RS & $4.337 .861,61$ & RS & $3.842 .323,09$ & RS & $4.599 .401,50$ & RS & $4.667 .105,73$ \\
\hline PIS Aliq. & & $1,65 \%$ & & $1,65 \%$ & & $1,65 \%$ & & $1,65 \%$ & & $1,65 \%$ & & $1,65 \%$ \\
\hline Vlr PIS & $\mathrm{RS}$ & $81.521,77$ & RS & $66.287,12$ & RS & $71.574,72$ & $\mathrm{RS}$ & $63,398,33$ & $\mathrm{RS}$ & $75.890,12$ & RS & $77,007,24$ \\
\hline Cofins Aliq. & & $7,60 \%$ & & $7,60 \%$ & & $7,60 \%$ & & $7,60 \%$ & & $7,60 \%$ & & $7,60 \%$ \\
\hline Vlr Cofins & RS & $375.494,20$ & RS & $305.322,47$ & RS & $329.677,48$ & RS & $292.016,55$ & RS & $349.554,31$ & RS & $354.700,04$ \\
\hline $\begin{array}{l}\text { Total do PIS } \\
\text { eCofins }\end{array}$ & & $457,015,97$ & RS & $371.609,58$ & RS & $401.252,20$ & RS & $355.414 \$ 9$ & RS & $425,444,64$ & RS & $431.707,28$ \\
\hline
\end{tabular}

Fonte: Dados da pesquisa

Nas Tabelas 6 e 7 visualiza-se os cálculos do recolhimento do PIS e da Cofins na empresa em foco, destacando-se os créditos que a empresa já faz o aproveitamento e ainda os créditos não utilizados que foram encontrados no decorrer deste projeto. 
Tabela 6 - Cálculo do PIS a recolher

\begin{tabular}{|c|c|c|c|c|c|c|}
\hline Créditos & Janeiro & Fevereiro & Março & Abril & Maio & Junho \\
\hline PIS sobre faturamento & RS $81.521,77$ & RS $66.287,12$ & RS $71.574,72$ & RS $63.398,33$ & RS $75.890,12$ & RS $77.007,24$ \\
\hline Créditos já utilizados & R\$3.919,37 & R\$2.616,58 & R $\$ 4.450,91$ & R\$2.894,90 & R\$5.108,88 & RS4.081,56 \\
\hline PIS à Recolher (1) & RS $77.602,40$ & RS $63.670,53$ & RS $67.123,80$ & RS $60.503,43$ & RS $70.781,24$ & RS $72.925,68$ \\
\hline Créditos não utilizados & R\$3.878,67 & RS3.286.81 & R\$3.851,76 & RS3.733,01 & R\$3.888,46 & RS3.720,30 \\
\hline PIS à Recolher (2) & RS $73.723,72$ & RS $60.383,73$ & RS $63.272,04$ & RS $56.770,42$ & RS $66.892,78$ & RS $69.205,38$ \\
\hline
\end{tabular}

Fonte: Dados da pesquisa

Tabela 7 - Cálculo do Cofins a recolher

\begin{tabular}{|c|c|c|c|c|c|c|}
\hline Créditos & Janeiro & Fevereiro & Março & Abril & Maio & Junho \\
\hline Cofins sobre faturamento & RS $375.494,20$ & RS $305.322,47$ & RS $329.677,48$ & RS $292.016,55$ & RS $349.554,51$ & RS $354.700,04$ \\
\hline Créditos já utilizados & RS18.052,86 & RS12.052,13 & R $\$ 20.501,17$ & R\$13.334,11 & RS23.531,82 & R $\$ 18.799,93$ \\
\hline Cofins à Recolher (1) & RS $357.441,34$ & RS 293.270,34 & RS $309.176,31$ & RS 278.682,45 & RS 326.022,70 & RS $335.900,11$ \\
\hline Créditos não utilizados & RS17.865,41 & RS15.139,23 & RS17.741,46 & RS17.194,46 & RS17.910,49 & RS17.135,93 \\
\hline Cofins à Recolher (2) & RS $339.575,93$ & RS 278.131,11 & RS 291.434,85 & RS 261.487,99 & RS $308.112,20$ & RS $318.764,17$ \\
\hline
\end{tabular}

Fonte: Dados da pesquisa

Na Tabela 6 tem se o Cálculo do PIS a recolher, com os créditos já aproveitados pela empresa o que resultou no valor a recolher de $\mathrm{R} \$ 77.602,40$ no primeiro mês do ano e na mesma tem se o valor a recolher com os créditos ainda não utilizados, que resultou no valor de $\mathrm{R} \$ 73.723,72$ também em janeiro. O mesmo se repete nos outros meses, podemos notar o valor expressivo que a empresa deixa de aproveitar nos créditos de PIS e Cofins.

$\mathrm{Na}$ Tabela 7 tem se o Cálculo da Cofins a recolher, como descrito no PIS, se os créditos fossem utilizados em sua totalidade, a empresa teria um aumento no seu faturamento. Isso pelo fato de recolher um valor menor para Receita Federal.

Tabela 8 - Apuração da diferença

\begin{tabular}{|c|c|c|c|c|c|c|}
\hline Valores & Janeiro & Fevereiro & Março & Abril & Maio & Junho \\
\hline PIS à Recolher (1) & RS $77.602,40$ & RS $63.670,53$ & RS $67.123,80$ & \begin{tabular}{ll|} 
RS $\quad 60.503,43$ \\
\end{tabular} & \begin{tabular}{ll|} 
RS & $70.781,24$
\end{tabular} & $\begin{array}{ll}\text { RS } & 72.925,68\end{array}$ \\
\hline Cofins à Recother (1) & RS $357.441,34$ & RS $293.270,34$ & RS $309 \cdot 176,31$ & RS $278.682,45$ & RS $326.022,70$ & RS $335.900,11$ \\
\hline Total a Recolher (l) & RS $435.043,73$ & RS $356,940,87$ & RS $376,300,12$ & RS $339.185,88$ & RS $396.803,94$ & RS $408.825,79$ \\
\hline PIS à Recolher (2) & RS $73.723,72$ & RS $60.383,73$ & RS $63.272,04$ & RS $\quad 56.770,42$ & RS $66.892,78$ & RS $69.205,38$ \\
\hline Cofins à Recother (2) & RS 339.575 .93 & RS 278.131,11 & RS 291.434,85 & RS 261.487,99 & RS 308.112 .20 & RS $318.764,17$ \\
\hline Total a Recolher (2) & RS 413.299 .65 & RS $338.514,84$ & RS $354.706,89$ & RS $318,258,41$ & RS 375.00498 & RS $387.969,55$ \\
\hline Diferenca & RS $21.744,08$ & RS $18.426,04$ & RS $21.593,22$ & RS $20.927,46$ & RS 21.79896 & RS $20.856,23$ \\
\hline
\end{tabular}

Fonte: Dados da pesquisa 
Por fim, tem-se na Tabela 8 a apuração da diferença, com o total a Recolher $1 \mathrm{o}$ valor total do PIS e da Cofins que será recolhido em cada mês do semestre pesquisado, com os créditos que já estão sendo utilizados e também pode-se baseando se no Total a Recolher 2, o que a empresa deixou de aproveitar ao longo destes 6 meses. Logo, percebe-se que a empresa deixou de recolher entre os meses de Janeiro à Junho um total de R \$ 125.345,99 referente aos créditos do PIS e da Cofins não aproveitados. Assim, esse valor poderia ser utilizado para novos investimentos na empresa, bem como para cursos de conhecimentos tributários para que os colaboradores pudessem fazer os aproveitamentos dos creditos mencionados.

\section{CONCLUSÕES}

O presente artigo tratou do aproveitamento de serviços que geram créditos de PIS e Cofins no regime não cumulativo de uma concessionária de automóveis. Com o objetivo geral de potencializar o aproveitamento dos tributos federais PIS/Pasep e Cofins quanto a apuração de seus créditos tributários incidentes, conforme apresentado no decorrer dos resultados, demonstrando todos créditos que podem ser aproveitados na apuração e ainda não estão sendo utilizados pela empresa.

Percebeu-se também que o estudo da legislação vigente em relação ao PIS e a Cofins se fez necessário para todas as possibilidades de aproveitamento desses créditos de forma a beneficiar a empresa. O PIS e a Cofins ganharam ênfase no estudo, pois, são tributos com valores de apuração significativos para a empresa, merecendo assim serem mensurados e analisados.

$\mathrm{Na}$ oportunidade, verificou que a empresa em foco merece uma atenção especial uma vez que além das atividades voltadas ao comércio, também executa serviços, não possuindo atualmente em seu quadro funcional uma pessoa com conhecimento especifico e aprofundado nesta legislação. Desta forma, os gestores desconhecem quais as operações geram créditos, e assim não os aproveitam na totalidade, aumentando o desembolso que a empresa faz no pagamento destes tributos.

Dessa forma, conclui-se que se torna indispensável, em função das inúmeras alterações na legislação, que os profissionais estejam em constante atualização, pois é fundamental que a empresa tenha alguém especializado e que possa dar a atenção 
devida para que todos os créditos sejam utilizados, não ficando na dependência de terceiros para a execução desta tarefa, uma vez que o valor dos créditos não aproveitados poderia servir de salário para a contratação de um especialista.

Por fim, devido à expressividade do valor encontrado, conforme Tabela 8, no que tange a apuração da diferença, no qual são comparados todos aqueles créditos que a empresa já faz o aproveitamento e também aqueles que ainda não são utilizados, a mesma deixou de aproveitar um total de $\mathrm{R} \$ 125.345,99$ referente aos créditos do PIS e da Cofins, que para os próximos exercícios também não seriam, caso não tivesse sido abordado por meio deste artigo. Dessa forma, sugere-se que a empresa utilize o valor encontrado na contratação de profissionais que entendam de planejamento tributário, pois este fator atua como um determinante para a sobrevivência das organizações.

\section{REFERÊNCIAS}

BEUREN, I. M. Como elaborar trabalhos monográficos em contabilidade: teoria e prática. 3. ed. São Paulo: Atlas, 2008.

BRASIL. Constituição da República Federativa do Brasil, de 1988. Disponível em: <http://www.planalto.gov.br>.

Congresso Nacional. Lei no 9.715, de 25 de novembro de 1998. dispõe sobre as contribuições para os Programas de Integração Social e de Formação do Patrimônio do Servidor Público-PIS/PASEP, de que tratam o art. 239 da Constituição e as Leis Complementares $\mathrm{n}^{\circ} 7$, de 7 de setembro de 1970, em $8^{\circ}$, de 3 de dezembro de 1970. Disponível em: <http://www.planalto.gov.br>.

. Congresso Nacional. Lei no $\mathbf{1 0 . 8 3 3 / 0 3}$, de 29 de dezembro de 2003. Dispõe sobre a alteração da Legislação Tributária Federal e dá outras providências. Disponível em: <http://www.planalto.gov.br>.

Congresso Nacional. Lei no $\mathbf{1 0 . 8 6 5 / 0 4}$, de 30 de abril de 2004. Dispõe sobre a Contribuição para os Programas de Integração Social e de Formação do Patrimônio do Servidor Público e a Contribuição para o Financiamento da Seguridade Social incidentes sobre a importação de bens e serviços e dá outras providências. Disponível em: <http://www.planalto.gov.br>.

Congresso Nacional. Lei no 11.727/08, de 23 de junho de 2008. Dispõe sobre medidas tributárias destinadas a estimular os investimentos e a modernização do setor de turism.o, a reforçar o sistema de proteção tarifária brasileiro, a estabelecer a incidência de forma concentrada da Contribuição para o PIS/Pasep e da Contribuição para o Financiamento da Seguridade Social - Cofins na produção e comercialização de álcool; Disponível em: <http://www.planalto.gov.br>. Acesso em 30 set. 2017.

Congresso Nacional. Lei Complementar $\mathbf{n}^{\mathbf{0}}$ 7, de 7 de setembro de 1970.

Institui o Programa de Integração Social, e dá outras providências. Disponível em: <http://www.planalto.gov.br>. Acesso em 30 set. 2017. 
Congresso Nacional. Lei Complementar n⿳ 70, de 30 de dezembro de 1991. Institui contribuição para financiamento da Seguridade Social, eleva a alíquota da contribuição social sobre o lucro das instituições financeiras e dá outras providências. Disponível em: <http://www.planalto.gov.br>. Acesso em 30 set. 2017.

. Congresso Nacional. Medida Provisória no 135, de 30 de outubro de 2003.

Altera a Legislação Tributária Federal e dá outras providências. Disponível em: <http://www.planalto.gov.br>. Acesso em 30 set. 2017.

BRAVO, A. M. O conteúdo constitucional da não-cumulatividade no Pis e na Cofins e o conceito legal de insumo. Revista da Receita Federal: estudos tributários e aduaneiros, vol.2, n.1, p. 208-240, 2015.

CHAVES, F. C.; MUNIZ, É. G. Contabilidade Tributária na Prática. São Paulo: Atlas, 2016.

DENCKER, A. F. M. Métodos e técnicas de pesquisa em turismo. São Paulo: Futura, 2000.

FABRETTI, L. C. Contabilidade tributária. 15. ed. São Paulo: Atlas, 2015.

GIL, A. C. Como elaborar projetos de pesquisa. 6. ed. São Paulo: Atlas, 2008.

OLIVEIRA, G. P. Contabilidade tributária. 4. ed. São Paulo: Saraiva, 2013.

PINTO, J.R.D. Imposto de Renda, Contribuições Administradas pela Secretaria da

Receita Federal e Sistema Simples. Edição especial. Conselho Regional de

Contabilidade do Rio Grande do Sul Porto Alegre: 2012.

Imposto de Renda, Contribuições Administradas pela Secretaria da Receita

Federal e Sistema Simples. Edição especial. Conselho Regional de Contabilidade do

Rio Grande do Sul Porto Alegre: 2012.

PORTAL TRIBUTÁRIO - PIS E Cofins: Aspectos gerais

<http://www.portaltributario.com.br/guia/pis_cofins.html> Acesso em: 21 mar. 2017.

RAUPP, F.M.; BEUREN, I. M. Metodologia da pesquisa aplicável as Ciências Sociais. 3.ed. São Paulo: Atlas, 2012.

RIBEIRO, O. M. Contabilidade geral fácil. São Paulo: Saraiva, 1999.

RICHARDSON, R. J. Pesquisa Social: métodos e técnicas. 3. ed. São Paulo: Atlas, 1999.

SANTOS, C. BARROS, S. F. Imposto de Renda Pessoa Jurídica para Contadores. 3. ed. São Paulo: IOB, 2008.

SMITH, A. A riqueza das nações. Trad. Alexandre Amaral Rodrigues e Eunice Ostrensky. 2. ed. Martins Fontes, 2003.

THOMAS, J.R.; NELSON, J.K.; SILVERMAN, S. J. Métodos de pesquisa em atividade física. 5. ed. Porto Alegre, 2007. 